\title{
Appraisal of the tire derived rubber (TDR) medium for wastewater treatment under aerobic and anaerobic conditions
}

\author{
Authors \\ Iffat $\mathrm{Naz}^{1}$, Nazia Khatoon ${ }^{1}$, Muhammad Ishtiaq Ali ${ }^{1}$, Devendra P. Saroj ${ }^{2}$,Syeda Ain-ul Batool ${ }^{1}$, \\ Naeem Ali ${ }^{1}$, Safia Ahmed ${ }^{1, *}$ \\ ${ }^{1}$ Department of Microbiology, Quaid-i-Azam University, Islamabad, 45320, Pakistan \\ ${ }^{2}$ Centre for Environmental and Health Engineering (CEHE), Faculty of Engineering and Physical Sciences
} University of Surrey, Surrey GU2 7XH, UK

*Corresponding Author

Email: safiamrl@yahoo.com

T: +92 (51) 90643009

F: +92 (51) 90644087

This article has been accepted for publication and undergone full peer review but has not been through the copyediting, typesetting, pagination and proofreading process, which may lead to differences between this version and the Version of Record. Please cite this article as doi: $10.1002 /$ jetb.4161 


\section{Abstract}

BACKGROUND: The present study evaluated the effectiveness and durability of TDR for biofilm development and related long term usage in fixed biofilm reactors for wastewater treatment.

RESULTS: TDR incubated $\left(30 \pm 2^{\circ} \mathrm{C}\right)$ with activated sludge showed comparatively higher biofilm development $(0.51 \mathrm{~g})$ under aerobic than under anaerobic $(0.42 \mathrm{~g})$ conditions after 7 weeks. During biofilm succession, a significant shift in bacterial community was observed from pathogenic to autotrophic after 4 weeks. The decreasing bacterial count (MPN index) ( $80 \%)$ ( $E$.coli and feacal coliforms) and COD, and BOD (70\% approx.) depicted diminishing organic load in sludge. While, changes in $\mathrm{pH}$ and nutrients like $\mathrm{NO}_{2}{ }^{-}, \mathrm{NO}_{3}^{-}, \mathrm{PO}_{4}^{3-}$ and $\mathrm{SO}_{3}{ }^{2-}$ indicated presence of other key-bacterial species with efficient nutrient consuming abilities in biofilm. Scanning Electron Microscopy showed few aberration and rich bacterial growth on treated TDR. Furthermore, detailed analysis through FTIR spectroscopy confirmed minor transformation in TDR under anaerobic conditions.

CONCLUSION: TDR proved to be considerably durable and cost effective support material that can be used in aerobic fixed biofilm reactors for wastewater treatment. However, operational conditions of the reactor should be optimized to keep the biofilm structure intact and for achieving desired wastewater treatment efficiency.

Keywords: Tire derive rubber (TDR); Biofilm; Microbial succession; Biological wastewater treatment 


\section{INTRODUCTION}

Wastewater treatment using attached growth biological process, under aerobic or anaerobic conditions, has been widely practiced. ${ }^{1}$ Attached growth reactor configurations applied in wastewater treatment include trickling filters, high rate plastic media filters, rotating biological contactors, fluidized bed biofilm reactors, airlift reactors, granular filters and membrane immobilized cell reactor. ${ }^{1,2}$

The formation of biofilm on support media is the essential part of attached growth processes; the microbial communities and their metabolic pathways are distinct in aerobic and anaerobic processes, resulting in their peculiar mechanisms of pollutants removal. $^{2}$ A biofilm is complex microbial derived sessile coherent community of cells adhere to surface. ${ }^{3,4}$ Formation of a static biofilm begins with the attachment of free-floating microorganisms to a surface. ${ }^{5}$ After adherence, bacteria produce matrix of hydrated extracellular polymeric substances (EPS) which mediates their adhesion to substrates and forms a cohesive, three-dimensional polymer network that interconnects and transiently immobilizes biofilm cells. ${ }^{6,7}$ Cell division and recruitment of new cells results in the growth and development of the biofilm communities, i.e. maturation, resulting in the formation of biofilm that expands to form a layer covering the surface. ${ }^{8}$ Widely used parameters for biofilm characterization during biofilm formation, detachment and composition on support media include gravimetric analysis parameters, such as, optical density, thickness, total cell count and weight. ${ }^{9,}{ }^{10}$ Some other techniques

also help to understand the biofilm formation process, i.e. Light microscopy ${ }^{11}$ Scanning electron microscopy (SEM), ${ }^{11}$ Confocal electron microscopy, ${ }^{12}$ Spectroscopic analysis, i.e. FTIR and NMR, and various molecular methods including GEL electrophoresis, ${ }^{13} 16$ S Ribosomal RNA sequencing, DGGE and FISH. ${ }^{6,14}$

Biofilm support media is one of the most critical factors by providing surface to biomass growth and also microbial attachment and contact with contaminants for removal. ${ }^{15}$ Different types of synthetic and natural materials are used as matrix media for bio-layer formation. Among various synthetic media, rubber has potential for application as biofilm support media, due to its physico-chemical properties. Tire rubber material can support microbial growth owing to its constant shape and durability. ${ }^{16}$ The recycled tire rubber has variable surface $\mathrm{pH}$, and it tends to maintain a specific gravity close to unity, with a hydraulic conductivity between $0.2-$ $0.8 \mathrm{~cm} / \mathrm{s}$, and a water adsorption capability between $5-10 \% .{ }^{17}$ Globally, more than 330 million waste tires are discarded each year. Such tires have become a serious source of waste to pollution. On the other hand, waste 
tires represent interesting source for activated carbons because of its high carbon content and is thought to be used as a supporting media in fixed film batch bioreactor. ${ }^{18}$

Tire-derived rubber (TDR) seems to be a valuable option for wastewater treatment; they can be easily obtained at low costs, and in large quantities. Moreover, several bioreactors with TDR, such as trickling filters, hybrid SGBR with TDR particles and anoxic TDR particle filters, have shown good performance efficiencies. TDR media provide a large surface area, high porosity, and they are generally resistant to biodegradation. ${ }^{19}$ Therefore, this work aims to study the biofilm progression on TDR media under aerobic and anaerobic conditions for biological wastewater treatment. This study covers a detailed investigation of the physiological activities and evaluation of most suitable stage of biofilm systems, by means of observing the changes in the chemical characteristics of sludge and the TDR material, and by analyzing the biodegradation potential under aerobic and anaerobic conditions. This study provides an insight into the possible applications of TDR material as supporting media in fixed biofilm reactor (FBR) for cost effective and efficient wastewater treatment.

\section{MATERIAL AND METHODS}

\section{Preparation and characterization of TDR media}

The TDR material (Bus radial tire) was cut into cubical pieces, with each having surface area of $21.95 \mathrm{~cm}^{2}$, to be used for microbial fixation. X-ray Photoelectron Spectroscopy (XPS) analysis was performed using a Thermo Fisher Scientific Theta Probe spectrometer (East Grinstead, UK) for elemental quantification of TDR media. XPS spectra were acquired using a mono-chromated Al Ka X-ray source $(\mathrm{h} v=1486.6 \mathrm{eV})$; an X-ray spot of $\sim 400 \mu \mathrm{m}$ radius was employed. Survey spectra were acquired by employing pass energy of $300 \mathrm{eV}$. High resolution core level spectra for $\mathrm{C} 1 \mathrm{~s}, \mathrm{O} 1 \mathrm{~s}, \mathrm{Ca} 2 \mathrm{p}$ and N1s were obtained with a Pass Energy of $50 \mathrm{eV}$. All other high resolution core level spectra were produced by employing a Pass Energy of $80 \mathrm{eV}$. All spectra were charge referenced against the $\mathrm{C} 1 \mathrm{~s}$ peak at $285 \mathrm{eV}$ to correct for charging effects during acquisition. Quantitative surface chemical analyses were calculated from the high resolution core level spectra following the removal of a nonlinear (Shirley) background. The manufacturers "Avantage" software was used, which incorporates the appropriate sensitivity factors and corrects for the electron energy analyzer transmission function.

\section{Development and characterization of biofilm on TDR media}

Activated sludge was sampled from wastewater treatment plant of Islamabad (Pakistan) in sterilized nalgean bottles $(1000 \mathrm{~mL})$ to be used as seed for colonization of bacterial community on TDR media. The bacteria 
present in the sludge were identified and characterized according to the Bergey's Manual of Determinative Bacteriology. ${ }^{20}$ The biofilm was developed on washed and sterilized TDR media by incubating it in same source of activated sludge $(300 \mathrm{~mL})$ under aerobic as well as anaerobic conditions at $30 \pm 2^{\circ} \mathrm{C}$. The experimental set-up consist of two sets of bioreactors i.e., small glass jars (height=19.05 $\mathrm{cm}$, radius $=6.95 \mathrm{~cm}$ ) with volumetric capacity of 2,891.93 $\mathrm{cm}^{3}$ packed with TDR support media (three TDR cubes in each reactor) for biofilm growth. One set of bioreactors was periodically agitated and covered with perforated material for maintaining aerobic environment, while another set was initially sparged with nitrogen gas $(5 \mathrm{~min})$ and then sealed with paraffin to create anaerobic conditions. Both sets of bioreactors were operated in batch mode without additional organic substrate source, in order to investigate the changes in the fixed film systems (both on the activated sludge constituents and TDR material itself).

\section{Characterization of activated sludge and biofilm growth}

During growth of microbes on TDR media, the sludge samples were collected at certain time intervals $\left(0,3^{\text {rd }}, 6^{\text {th }}\right.$ and $9^{\text {th }}$ weeks) from both aerobic and anaerobic experimental setups, and were subjected to microbiological analysis (MPN index $)^{20}$ of pathogenic indicators and chemical analyses, includes chemical oxygen demand (COD) and Biochemical oxygen demand $\left(\mathrm{BOD}_{5}\right)$, Nitrite $\left(\mathrm{NO}_{2}^{-}\right)$, Nitrate $\left(\mathrm{NO}_{3}^{-}\right)$, Phosphate $\left(\mathrm{PO}_{4}^{-}\right)$and sulphate $\left(\mathrm{SO}_{4}{ }^{-}\right)$by standard methods. ${ }^{21}$ Changes in $\mathrm{pH}$ of sludge was determined by digital $\mathrm{pH}$ meter (D-25 Horiba).Statistical analysis was carried out by Microsoft excel program 2007. All the analyses (chemical tests) were conducted in triplicates and in order to find out treatment efficiencies, the mean values of each parameter tested at different weeks of incubation were compared with its zero time value by t-test and $P<0.05$ was considered as minimum value for statistical significance. 


\section{Monitoring of microbial growth of biofilm on TDR media}

The microbial succession on TDR media was monitored by Gravimetric (weight and optical density), microscopic and heterotrophic plate count ( $\mathrm{HPC} \mathrm{mL}^{-1}$ of selected bacteria) under aerobic and anaerobic conditions for nine weeks at regular interval.

\section{Estimation of biofilm weight}

Both dry and wet weights of biofilm on TDR media were estimated by using digital weighing balance (Scout ${ }^{\mathrm{TM}}$ pro, OHAUS). The wet weights of biofilm were taken after soft rinsing with distilled while dry weight was determined after soft rinsing with distilled water followed by oven dry (Toyo Seisakusho Co.) at $60^{\circ} \mathrm{C}$ till accomplishment of constant value. ${ }^{22}$ Finally the weight of the biofilm on matrix under both conditions was calculated by means of difference.

Estimation of biofilm optical density

The biofilm was also quantified by their optical density (OD). The TDR media supporting biofilms were first rinsed with sterilized water to ensure the removal of any material form sludge on its surface. Then microbial growth was removed from TDR media in $0.9 \%$ saline by sonication (Sonicator, Yamato) for 15 minutes. Finally the spectrophotometric absorbance (Agilent UV-Visible Spectrophotometer 8453) of dissolved biofilms was recorded at $550 \mathrm{~nm}$ wavelength $\left(\mathrm{OD}_{550}\right)$ using saline as blank.

\section{Estimation of heterotrophic plate count (HPC $\left.\mathrm{mL}^{-1}\right)$}

The HPCmL ${ }^{-1}$ of biofilm on TDR media from sludge were determined by conventional serial dilution method. The biofilm dissolved in $0.9 \%$ saline was serially diluted up to $10^{-5}$ spread plated on the selective growth media (i.e., Nutrient agar, Eosin methylene blue agar, MaConecky agar, Salmonella shigella agar, Pseudomonas citrimide agar, Mannitol salt agar, Blood agar etc.) and incubated at $37^{\circ} \mathrm{C}$ for $24-48 \mathrm{~h}$. The microbial growth appeared on specific media was enumerated in terms $\mathrm{HPCmL}^{-1}$ (pathogenic indicators). Pure cultures from these plates were identified by colony morphology, microscopic (gram's staining and shapes) and biochemical tests (Triple sugar iron test for Lactose/Glucose fermentation, Indole and $\mathrm{H}_{2} \mathrm{~S}$ test, Citrate utilization test, Nitrate reduction test, Catalase test, Carbohydrate fermentation, Urease test and Methyl red Vogas Proskauer test).

\section{Biodegradation analysis of TDR media}


Scanning electron microscopy (SEM)

For scanning electron microscopic (SEM) analysis, thin rubber section with biofilms were taken from the batch reactor and immersed in $0.2 \mathrm{M}$ phosphate buffer. The samples were then washed twice and fixed. The fixed samples were dehydrated $\left(\mathrm{KADA}^{\circledR} 85 \mathrm{U} / \mathrm{SMD}\right)$ for 2 minutes and coated with gold. The coated samples were examined under a SEM (model JEOL JSM-5910) at 1000x and 3000x.

Fourier transform infrared spectroscopy (FTIR)

FTIR analysis of TDR media was carried out before and after fixation of biofilm in order to determine the degradation during biofilm expansion under aerobic and anaerobic environments. For degradative analysis of media, the biofilms were removed from the support media by $0.9 \%$ saline and then TDR cubes were washed with distilled water before subjected to Fourier Transform Infrared Spectroscopy (FTIR, Merlin 56). The spectra of FTIR were scanned at 600 to $4000 \mathrm{~cm}^{-1}$ in triplicate.

\section{RESULTS AND DISCUSSION}

The present investigation deals with the succession of microbial biofilm on TDR media, the analysis of biofilm physiological activities and capacity to cause biodegradation of media after exposure to activated sludge under aerobic and anaerobic conditions. This study also revealed the most suitable stage (metabolically active) of

microbial growth having maximum potential to treat wastewater and more compatible, durable and inert media to be used in FBR. It is necessary to select best supporting media and active stage of biofilm to be employed in the FBRs because their treatment efficiency depends on the microbes and filter media. ${ }^{23,24}$

\section{Characterization of TDR medium by XPS}

Using XPS, it became achievable to identify elements i.e. carbon (83.5\%), oxygen (9.5\%), silicon (3.7\%), nitrogen $(2.96 \%)$, sulpher $(0.30 \%)$ and zinc $(0.13 \%)$ both in small and large areas of the tested TDR material (Fig 1). TDR filter media has potential (non toxic elements) to maintain growth of a biofilm which can biologically oxidize organic content of sludge. However, the presence of chlorine, sulfur, silicon, calcium, oxygen, zinc and magnesium was observed in TDR particles used as biofilter. ${ }^{25}$

\section{Assessment of microbiological changes in sludge during biofilm development on TDR medium}

Development of biolayer on TDR media exerted microbiological and physico-chemical changes in the feed sludge. The microbiological changes in the sludge were due to fixation of bacteria on TDR media and physico- 
chemical changes was owing to (free and fixed) physiological activities of microbes. Thus investigations were also focused on the bacteriological analysis of sludge during succession of biofilm on TDR media by considering qualitative and quantitative analysis of indicator bacteria before and after nine weeks of duration under aerobic and anaerobic conditions.

The enumeration (strength) of indicator microbes were conducted by MPN per 100mL tests (MPN index for fecal coliforms and for E. coli (considering 95\% confidence limits). A significant reduction in MPN for fecal coliform (97.5\% and $99 \%$ in aerobic and anaerobic environments respectively) was detected after 9 weeks (Table 2). Similarly MPN results of E. coli showed reduction to $150(86.3 \%)$ and $210(81 \%)$ per $100 \mathrm{~mL}$ under aerobic and anaerobic conditions respectively from initial count of $>1100 / 100 \mathrm{~mL}$ (Table 2). This diminution in pathogenic indicators was ascribed to their adhesion in the form of biofilms and also to the depletion (oxidation in aerobic and digestion in anaerobic environments) of organic nutrients in the sludge with passage of time. The drop off in pathogenic microbial consortia in wastewater is due to maintenance in the biofilm by association and are later detached or deactivated by predation or natural die off practice. ${ }^{26}$

\section{Assessment of chemical changes in sludge during biofilm development on TDR medium}

Various physico-chemical parameters of sludge were monitored at regular interval $\left(0,3^{\text {rd }}, 6^{\text {th }}\right.$ and $9^{\text {th }}$ weeks $)$ in order to determine microbial activities. These parameters were considered for recognition of invading bacteria of wastewater treating biofilm by other investigators. ${ }^{27}$ The COD indicated total carbon content (organic and inorganic) of sludge before and after the biofilm development on TDR. Initially the mean COD of sludge was $296 \mathrm{mg} \mathrm{L}^{-1}$ and then significantly reduced $\left(\begin{array}{ll}p & 0.05\end{array}\right)$ to 79 and $89 \mathrm{mg} \mathrm{L}^{-1}$ after nine weeks under aerobic and anaerobic conditions respectively, as shown in Fig. 2(A). Under aerobic conditions, COD showed considerable decrease $(p=0.015)$ and comparatively more drastic percent removal of COD was observed in the sludge (56.6\%) having six week old biomass growth on media as compared to $3^{\text {rd }}$ and $9^{\text {th }}$ weeks old biofilm $(28.8$ and $72.9 \%$ respectively). Thus six weeks old biofilms can be considered in physiologically active phase regarding COD removal. While, in case of anaerobic condition, a highly significant reduction $(p=0.013)$ was noticed in COD concentrations after nine weeks, (Fig. 2A). Thus decrease of 73.32 and $69.9 \%$ COD of sludge after nine weeks was exerted by aerobic and anaerobic rubber biofilm respectively. Similar COD reduction in FBR was

observed by various researchers. ${ }^{28-31} \mathrm{~A}$ decrease in COD concentration was due to efficient degradation of organic compounds (mass transfer) by activity of microbes in the sludge and biofilm. ${ }^{32,33}$ 
The average BOD of activated sludge prior to experiment was $198.56 \mathrm{mg} \mathrm{L}^{-1}$ and noticeably decreased $(p$ $0.05)$ to $106.08(46.6 \%)$ and $53.72 \mathrm{mg} . \mathrm{L}^{-1}(72.9 \%)$ after six and nine weeks of biofilm development under aerobic conditions. While, six and nine weeks anaerobic biofilms exerts decline of BOD to 111.52 (43.8\%) and $60.53 \mathrm{mg} \mathrm{L}^{-1}(69.5 \%)$ respectively, as shown in Fig. 2(B). The BOD was significantly reduced in both aerobic ( $p$ $=0.017)$ and anaerobic $(p=0.014)$ experimental operates after nine weeks of microbial growth on TDR media. Initial high concentration of BOD of activated sludge was due to the presence of organic compounds and bacteria that used large amount of oxygen for their oxidation. Reduction in its concentration during nine weeks of biofilm development indicates high biodegradation of organic matter in sludge. Experimentally it was verified that in FBR, reduction in BOD was due to microorganisms present within biofilm. ${ }^{34}$ Generally, a significant though inverse correlation exist between BOD or COD with DO. Similar pattern was followed in the present investigation where the average initial concentration of DO in activated sludge was raised from 1.20 to $3.2 \mathrm{mg} \mathrm{L}^{-1}(210 \%)$ under aerobic environment after 9 weeks of incubation. This raise in DO was facilitated through agitation with succeeding degradation rates of organic matter in the sludge. Contrarily, the DO levels of the anaerobic experimental setup was reduced $(27 \%)$ to $0.74 \mathrm{mg} \mathrm{L}^{-1}$ which clearly indicated exhausting of DO level in the sludge due to oxidation of organic and inorganic compounds (Fig. 2C).

During succession of the microorganisms on rubber the $\mathrm{pH}$ values of sludge showed slight deviation from 7.04 to 7.18 after one week, and reached to $\mathrm{pH} 7.51$ in nine weeks under aerobic conditions. While, under anaerobic conditions it remained in neutral range (7.04 - 7.23) until ninth week of biofilm growth (Fig. 2D). This pH range is appropriate for biological activities. Also, research on activated sludge systems has shown that bacteria are activated in $\mathrm{pH} 4-9 .{ }^{35}$ However, high $\mathrm{pH}$ has positive effect on wastewater treating processes, as at high $\mathrm{pH}$, bacteria change its isoelectric state, resulting in increase of the active sites on cells, exotic polymers, and as a result improvement in the ability for bridging and biofloculation. ${ }^{36}$

Changes in various nutrient concentrations were also considered during biofilm growth on TDR in order to explore the existence (physiological activities) of autotrophic microbes. Initial average concentration of $\mathrm{NO}_{2}^{-}$ was $0.126 \mathrm{mg} \mathrm{L}^{-1}$ and then showed decrease under aerobic $\left(0.021 \mathrm{mg} \mathrm{L}^{-1}\right)$ and anaerobic $\left(0.016 \mathrm{mgL}^{-1}\right)$ conditions after nine weeks (Fig. 3A). On the other hand the concentration of $\mathrm{NO}_{3}{ }^{-}$showed gradual increase from its mean value of $0.372 \mathrm{mg} \mathrm{L}^{-1}$ during fixation and maturation of biofilm and reached to 0.5082 and 0.6816 $\mathrm{mgL}^{-1}$ under aerobic and anaerobic conditions respectively after nine weeks (Fig. 3B). The decline in concentration of $\mathrm{NO}_{2}^{-}$and raise in $\mathrm{NO}_{3}{ }^{-}$was attributed to the nitrite oxidizing activity of nitrifying bacteria 
(Nitrosomonas sp. and Nitrobactor sp.). These fluctuations in concentration of nitrite and nitrate in the sludge by the existence of both kinds of bacteria was also reported by many other researchers. ${ }^{30,36}$, However, E. coli and Pseudomonas sp. are also reported to carry out nitrification. ${ }^{37}$ Thus, E. coli and P. aerouginosa observed in the developing biofilm on TDR might be responsible of some extent of nitrification.

Phosphate $\left(\mathrm{PO}_{4}^{-3}\right)$ concentration was $0.016 \mathrm{mgL}^{-1}$ in activated sludge before subjected to biogrowth on TDR media. Its concentration was slightly decreased $(p=0.05)$ and reached to 0.021 and $0.007 \mathrm{mgL}^{-1}$ after nine weeks under aerobic and anaerobic conditions respectively (Fig. 3C). This showed that polyphosphorus accumulating bacteria (PAO's) might be present in the biofilm that used soluble phosphorus as a substrate. The removal of phosphate being due to the intracellular accumulation by the organisms was confirmed by microscopic observation. ${ }^{38}$ Microbes utilize phosphorus during cell synthesis and energy transport. As a result, 10 to $30 \%$ of all influent phosphorus is removed during secondary biological treatment. ${ }^{39,}{ }^{40}$ Peng et al. ${ }^{41}$ reported denitrifying phosphorous removal in a sequencing batch reactor (SBR) operated using a real-time step feed strategy.

Average concentration of sulphate was $0.220 \mathrm{mgL}^{-1}$ in the sludge and after nine weeks during the succession of biolayer on media it showed decrease $(p=0.05)$ to 0.084 and $0.074 \mathrm{mgL}^{-1}$ under aerobic and anaerobic environments respectively (Fig. 3D). Such decline of 61.5 and $66.3 \%$ in aerobic and anaerobic experimental operates was owing to microbial exploitation of sulphates. ${ }^{42}$ Pungent odor was noticed in the experimental set up under anaerobic condition due to reduction of sulphates to hydrogen sulfide. 


\section{Assessment of biofilm growth on TDR medium}

A significant increase in gravimetric weight of biofilm was observed under aerobic and anaerobic environments. Under aerobic conditions wet weight of biofilm increased $(54.9 \%, \mathrm{p} \quad 0.05)$ up to $7^{\text {th }}$ week from $0.23 \pm 0.01$ to $0.51 \mathrm{~g}$. While, significant increase $(95.1 \%, p \quad 0.01)$ was also observed in dry weight $(0.02 \pm 0.01$ to $0.41 \mathrm{~g})$ as shown in Fig. 4(B). Similarly, under anaerobic conditions the wet weight increased from $0.31 \pm 0.01$ to $0.42 \mathrm{~g}$ $(26.2 \%)$. On the other hand, dry weight of biofilm showed considerable increase $(84 \%, p \quad 0.01)$ from $0.04 \pm$ 0.001 to $0.25 \mathrm{~g}$ in seven weeks and then slight decreased $(0.18 \pm 0.001 \mathrm{~g})$ after nine weeks (Fig. 4C). The increase in weights (wet and dry) of biofilm was ascribed to large surface area provided rough texture for quick colonization, division (growth and maturation) of fixed cells and secretion of glue like layer of EPS during attachment of microbes on supporting materials. The increased growth of biomass with passage of time was also shown by increased OD of biofilm. OD was most reliable method to quantify total biofilm and there was a linear relation between optical density and dry weight and OD is proportional to strength of bacteria within fixed ranges of cell size and shape. ${ }^{43,44}$ Under aerobic conditions biofilm showed drastic increase in OD $_{(550)}$ after 1 st week $(0.249 \pm 0.0050)$ followed by slow change till $7^{\text {th }}$ week $(0.186 \pm 0.0056)$ which further decreased due to detachment, and reached to $0.14806 \pm 0.0062$ after nine weeks. Fluctuations in $\mathrm{OD}_{(550)}$ of anaerobic biofilm on TDR media was recorded i.e. $3^{\text {rd }}$ week OD was $0.546 \pm 0.0023$ followed by reduction after $5^{\text {th }}$ week $(0.214 \pm$ $0.007)$ and again increased in seven weeks $(0.5739 \pm 0.0002)$ old biofilm. Then it decreased after nine weeks $(0.119 \pm 0.004)$ of experiment (Fig. 4A). The increase in biofilm weight and OD were also confirmed by SEM analysis. Scanning electron microscopy is a well-established fundamental technique to examine the morphology of bacteria adhered on surfaces, the topography of the material surface, and the associations between them. Various conclusions about biofilm development, composition, distribution, and relationship to substratum have been resultant from SEM. ${ }^{45}$ SEM micrographs revealed the high surface area due to porous nature of the TDR media (Fig. 5A). Large surface area will sustain more microbial growth. Fig. 5(B) illustrates primarily $\left(3^{\text {rd }}\right.$ week biofilm) few bacteria on the media but six weeks old biofilm has some cocci and bacilli of various sizes under aerobic conditions, as shown in Fig. 5(C). While Fig. 5(D) revealed considerable increase in aerobic bacterial growth $\left(9^{\text {th }}\right.$ week biofilm) on TDR media. Fig. 5(E) shows three weeks old biogrowth having few bacilli on the surface of TDR media. While Fig. 5(F) illustrating drastic increase in bacilli of larger sizes during succession of the biofilm after six weeks. On the other hand, nine weeks old biofilm has bacteria (mostly rods) embedded deep in thick EPS, as shown in Fig. 5(G). Thus SEM revealed constant enlargement in the growth of the biofilm 
during its succession on TDR media. But pattern of biofilm expansion was different under anaerobic as compared to aerobic state.

\section{Assessment of heterotrophic plate count (HPC.mL ${ }^{-1}$ )}

Microbiological characterization of sludge (before subjected to biofilm growth) on the basis of colony morphology, microscopic and biochemical tests showed the presence of 14 bacterial strains. Most of them were gram negative rods (Escherichia coli, Pseudomonas aeruginosa, Enterobacter aerogenes, Salmonella typhimurium, Proteus vulgaris, Alcaligenes faecalis, Shigella dysenteriae, and Klebsiella pnuemoniae) and five were gram positive (Bacillus subtilis, Staphylococcus aureus, Micrococcus luteus, Streptococcus lactis, and Corynebacterium xerosis). Among Gram positives different microscopic shapes were revealed viz., short chain rods (B. subtilis), diplococcic (M. luteus), short chain cocci (S. lactis) and Phalliside rods (C. xerosis). A number of invading primary biofilm colonizers on TDR media were gram negative, flagellated, aggregated rather than being a single layer cells. Such type of bacteria was also reported from wastewater treating fixed biofilms. ${ }^{46,47}$ The composition and development of such biogrowth depend on many factors (nature of media, availability of water, organics) and microbes in the sludge. Some bacterial species i.e. E. coli, P. aeruginosa, S. typhimurium and $S$. dysenteriae were selected to be monitored by their viable colony count $\left(\mathrm{HPC} \mathrm{mL}^{-1}\right)$ on TDR media under aerobic and anaerobic conditions for nine weeks in order to explore the exact time of microbial shift from pathogenic biofilm. According to Uhlich et al. ${ }^{48}$ these Enterobacters (E. coli, Salmonella and Shigella) have curly adhesive fibers which support biofilm formation to abiotic surfaces under different conditions and biofilm formation capacities of $E$. coli $(\mathrm{K}-12)$ were directly related with its ability to swim with flagella. ${ }^{49}$

Aerobically developed biofilm showed an increase of E. coli HPC $\mathrm{mL}^{-1}$ till $2^{\text {nd }}$ week $\left(2.9 \times 10^{3}\right)$ followed by a decrease in four weeks $\left(1.2 \times 10^{3}\right)$ and finally vanished in five week's old biofilms. The second pathogen, $S$. typhimurium was identified only till $2^{\text {nd }}$ week $\left(1 \times 10^{2}\right.$ and $\left.1.5 \times 10^{2}\right)$. While, S. dysenteriae was noticed in first three weeks with HPC $\mathrm{mL}^{-1} 1.5 \times 10^{2}, 3.7 \times 10^{2}$ and $1 \times 10^{2}$ respectively (Fig. 6A). Under anaerobic conditions, E. coli was noticed till $4^{\text {th }}$ week $\left(\mathrm{HPC} \mathrm{mL}^{-1} ; 3.6 \times 10^{3}\right)$ whereas highest count of $S$. typhimurium was recorded in two weeks old biofilm $\left(1.5 \times 10^{2}\right)$ and then disappeared after $3^{\text {rd }}$ week. The third pathogenic indicator $S$. dysenteriae was found till $3^{\text {rd }}$ week $\left(1.2 \times 10^{2}\right)$ (Fig. 6A). But, P. aeruginosa was not seen on rubber media under both aerobic and anaerobic conditions till nine weeks (Fig. 6A and B). However, it was previously reported that $P$. aeruginosa canform biofilm under any condition that allow growth. ${ }^{50}$ Thus, it was evident from present study that TDR media cannot support $P$. aeruginosa growth. The disappearance of all selected 
pathogens in five weeks old biofilm, constant increase in weight and OD of biofilm, reduction in chemical parameters (COD and BOD) and various nutrients $\left(\mathrm{NO}_{2}{ }^{-}, \mathrm{NO}_{3}{ }^{-}, \mathrm{PO}_{4}{ }^{3-}\right.$ and $\left.\mathrm{SO}_{3}{ }^{2-}\right)$ in sludge pointing towards the microbial shift from pathogenic indicators towards other microbes (both heterotrophic and autotrophic) involved in formation of biofilm on TDR.

\section{Assessment of biodegradation of TDR medium}

Surface examination of rubber media through SEM showed erosions and extensive roughening on the top surface in comparison to control (Fig. 6). The Cracks in the films were infested with microbial growth. Such colonization and adhesion by microorganisms are a fundamental prerequisite for biodegradation of the polymer. ${ }^{51}$ The rubber media showed clear surface erosion, cracks, holes and initiation points, indicating that the polymer has become brittle due to microbial growth on the surface. Surface cracks of media become wider under anaerobic environment than under aerobic condition (Fig. 6F). Park et al. ${ }^{19}$ also reported TDR media support biological activity in a variety of wastewater treatment applications. Park et al. ${ }^{25}$ also used the technique of SEM to study the microbial population on tire derived rubber particles (TDRP) used as biofiltration media for hydrogen sulfide odor removal. Moreover, SEM analysis of the TDR media collected from FBR showed the homogeneous and abundant microorganisms on every surface. Therefore, the applicability of TDR as the biofiltration media can be very comprehensive in environmental field. ${ }^{52}$ Thus TDR media supporting physiologically energetic biofilm can be used for wastewater treatment in aerobic attached growth reactors. Hirai et al. ${ }^{53}$ also reported that good media has high porosity, large surface area, experience little change in character over long operation, low density etc.

The biodegradation of TDR was evaluated through FTIR as it was previously investigated. ${ }^{54-57}$ Under aerobic condition no significant changes occurred in the FTIR spectrum till $4^{\text {th }}$ week, however, few new peaks were developed at regions of $1541 \mathrm{~cm}^{-1}$ and $1464 \mathrm{~cm}^{-1}$ indicating the production of $\mathrm{C}=\mathrm{C}$ after $5^{\text {th }}$ and $6^{\text {th }}$ week. Additionally, a couple of peaks also referred development of C-H (SP3 hybridization) at 2861 and $2921 \mathrm{~cm}^{-}$ ${ }^{1}$ (Fig. 7A). Similar bonding patter i.e., C-H (SP3 hybridization) was appeared at $2915.28 \mathrm{~cm}^{-1}$ and $2847.50 \mathrm{~cm}^{-1}$ in FTIR spectrum after $1^{\text {st }}$ week under anaerobic condition. A sharp peak appeared at $2168.58 \mathrm{~cm}^{-1}$ showing terminal alkynes production and two new peaks developed at 1635.06 and $1543.94 \mathrm{~cm}^{-1}$ indicating $-\mathrm{NH} 2$ bending. After $3^{\text {rd }}$ week a broader peak developed at $3052 \mathrm{~cm}^{-1}$ denoting carboxylic acid production by oxidation. After $4^{\text {th }}$ week peaks showing more acid production and saturation through development of single 
bond $\mathrm{C}-\mathrm{H}$ i.e. sp3 hybridization (Fig. 7B). It was obvious that microbial succession caused limited biotransformation in TDR although it was higher under anaerobic compared to aerobic experimental condition.

Many previous reports have also established the biodegradation or biotransformation of natural and synthesis rubber, however, synthesis or blended form of rubber was prone to less biodegradation. ${ }^{58-63}$ The chemical changes in rubber have been linked with oxidative breakdown of the polymeric structures (isoprene, styrene, neprene and butadiene) by extracellular oxidative enzymes leading to production of aldehyde and/or carbonyl groups. In this reference the role of bacterial species like Nocardia sp. strain 835A, ${ }^{64}$ Pseudomonas aeruginosa AL98, ${ }^{65}$ Bacillus sp. SBS25, ${ }^{66}$ Streptomyces sp. strain K30 and Xanthomonas sp. strain $35 \mathrm{Y}^{63}$ have been well established. The durability of TDR depends upon its strong polymeric nature combined with different adhesives, retardants, and vulcanizing agents. Limited bio-transformation of surface composition of TDR indicated that it can be a valuable support material in aerobic FBR for long term usage in wastewater treatment.

Additionally, the results also highlighted the magnitude of microbially mediated biodegradation of TDR at sites where solid waste containing discarded tires and related polymer is dumped in soil. As synthetic rubber biodegradation has proved to be a very slow process. ${ }^{61}$ So, therefore, the natural phenomenon of bioremediation of polymeric compounds can be further stimulated by augmenting relevant microbes by supplementing their nutritional requirements in the natural environments.

\section{CONCLUSIONS}

Monitoring of the microbial succession on TDR media from sludge showed maximum growth stage at sixth week in both aerobic and anaerobic conditions. The observations on the changes in activated sludge constituents and TDR material itself showed remarkable influence of both aerobic and anaerobic conditions. A significant reduction in various chemical parameters $(\mathrm{COD}, \mathrm{BOD})$ of sludge has been observed, on account of undergoing physiological activities of microorganisms. Decrease of $\mathrm{HPC} \mathrm{mL}^{-1}$ (pathogenic indicators) in biofilm and MPN index (fecal coliforms and E. coli) of sludge represented a shift from pathogenic indicators to beneficial microbes for removal of organic contaminants in the sludge. TDR media showed durability under aerobic condition as observed by biodegradation investigation (SEM and FTIR) and can be employed as biofilter media in aerobic FBR for wastewater treatment. Therefore, the aerobic condition in the biofilm system with TDR media can ensure the efficiency and durability of the bioreactor components. However, the application of TDR 
media in anaerobic bioreactors requires further research in order to investigate the media replacement and posttreatment strategies after anaerobic treatment step.

\section{ACKNOWLEDGMENTS}

This research project is funded by higher education commission of Pakistan (HEC) under Pak-US joint academic \& research program (2009-10). Authors sincerely acknowledge Dr. Steven Hinder (Materials Science and Engineering, University of Surrey, UK) for his guidance in XPS analysis of rubber media during research visit of Mrs Iffat Naz under International Research Support Programme (IRSIP) sponsored by HEC.

\section{REFRENCES}

1 Loupasaki E and Diamadopoulos E, Attached growth systems for wastewater treatment in small and rural communities: a review. J Chem Technol Biotechnol 88: 190-204 (2013).

2 Hens M, Loosdrecht MCMv, Ekama GA and Brdjanovic D, Biological wastewater treatment: principles, modelling and design, IWA Publishing, London (2008).

3 Characklis WG, Kinetics of microbial transformation in biofilms, ed by Characklis and K. C. Marshal KC, Wiley and Sons, New York, pp 233-264 (1990).

4 Costerton JW, Introduction to biofilm. Int J Antimicrol Ag 11: 217-221 (1999).

5 Gottenbos B, Van-der Mei HC and Busscher HJ, Models for studying initial adhesion and surface growth in biofilm formation on surfaces. Method Enzymol 310: 523-534 (1999).

6 Stewart PS, Griebe T, Srinivasan R, Chen CI, Yu FP and McFeters GA, Comparison of respiratory activity and culturability during monochloramine disinfection of binary population biofilms. Appl Environ Microbiol 60: 1690-1692 (1994).

7 Flemming HC, Natural history of bacteria, biofilms and surfaces. In International Symposium on Membrane Biofouling 'Science and Solutions', Arizona, USA, 28-30 April 2010, (2010). http://www.ismb-2010.com/speaker_abstracts/flemming_abs1.pdf [accessed 6 August 2012].

8 Kumar CG and Anand SK, Significance of microbial biofilms in food industry: a review. Int $J$ Food Microbiol 42: 9-27 (1998).

9 Bakke R and Olsson PQ, Biofilm thickness measurements by light microscopy. J Microbiol Meth 5: 93-98 (1986).

10 Lazarova V and Manem J, Biofilm characterization and activity analysis in water and wastewater treatment. Water Res 26: 2227-2245 (1995). 
11 Denkhaus E, Meisen S, Telgheder U and Wingender J, Chemical and physical methods for characterization of biofilms. Microchimica Acta 158: 1-27 (2007).

12 Sambrook J and Russell D, Molecular cloning: A laboratory manual. 3rd edn. Cold Spring Harbor Laboratory Press, New York pp 223-226 (2001).

13 Willey JM, Sherwood LM and Woolverton CJ, Prescott, Harley Klein's Microbiology. 7th edn. McGraw-Hill, New York (2008).

14 Shareefdeen Z and Singh A, Biotechnology for odor and air pollution control. Springer, New York (2005).

15 Motta O, Proto A, Carlo FD, Caro FD, Utilization of chemically oxidized polystirene as cosubstrate by filamentous fungi. Int J Hyg Envir Heal 212: 61-66 (2008).

16 Seda JH, Lee JC and Carraro JA, Beneficial use of waste tire rubber for swelling potential mitigation in expansive soils. GSP 172, DOI.org/10.1061/40916 (235)5. Denver, ASCE (2007).

17 Moo-Young H, Sellasie K, Zeroka D and Sabnis G, Physical and chemical properties of recycled tire shreds for use in construction. J Environ Eng 129: 921-929 (2003).

18 Ariyadejwanich P, Tanthapanichakoon W, Nakagawa K, Mukaim SR and Tamon H, Preparation and characterization of mesoporous activated carbon from waste tires. Carbon 41: 157-164 (2003).

19 Park J, Ellis TG and Lally M, Evaluation of tire derived rubber particles for biofiltration media. In Proceedings of the Water Environment Federation 9: 3217-3230 (2006).

20 Bergey JH, Holt GJ, Sneath PH and Krieg NR, Bergey's Manual of Determinative Bacteriology, 9th edn. Lippincott Williams and Wilkins, Baltimore, USA (1994).

21 APHA, Standard Methods for the Examination of Water and Wastewater, 19th edn. American Public Health Association/American Water Works Association/Water Environment Federation, Washington, DC (1995).

22 An YH and Friedman RJ, Laboratory methods for studies of bacterial adhesion. J Microbiol Methods 30(2): 141-152 (1997).

23 Wang J, Shi H and Qian Y, Wastewater treatment in a hybrid biological reactor (HBR): effect of organic loading rates. Process Biochem 36: 297-303 (2000).

24 Leonard M, Biotransformation of sewage in a trickling filters. Foundation for Research Science and Technology's Envirolink Scheme. Client Report CSC 0906. (2009). http://www.envirolink.govt.nz/PageFiles/65/826-GSDC66.pdf [accessed 20 December 2011]. 
25 Park J, Eric AE and Ellis TG, Development of a Biofilter with Tire-Derived Rubber Particle Media for Hydrogen Sulfide Odor Removal. Water Air Soil Poll 215: 145-153 DOI 10.1007/s11270-0100466-1.(2011).

26 Anderson S, Gunaratna KR, Carl JL and Gunnel D, Biofilm formation and interactions of bacterial strains found in wastewater treatment systems. FEMS Microbiol Lett 283: 83 (2008).

27 Anderson S, Characterization of Bacterial Biofilms for Wastewater treatment. Royal Institute of Technology School of Biotechnology, Stockholm, TRITA-BIO Report 2009:3 ISSN 1654-2312 (2009).

28 Mann AT and Stephenson T, Modelling biological aerated filters for wastewater treatment. Water Res 31: 2443-2448 (1997).

29 Evangelho MR, Gonc MMM, Alves S, Anna JGL and Villas-Bo RC, A trickling filter application for the treatment of a gold milling effluent. Int J Miner Process 62: 279-292 (2000).

30 Sakuma T, Jinsiriwanit S, Hattori T and Deshussesa MA, Removal of ammonia from contaminated air in a biotrickling filter: Denitrifying bioreactor combination system. Water Res 42: 4507-4513 (2008).

31 Naz I, Batool SAU, Ali N, Khatoon N, Atiq N, Hameed A and Ahmed S, Monitoring of growth and physiological activities of biofilm during succession on polystirene from activated sludge under aerobic and anaerobic conditions. Environ Monit Assess 1-12 DOI 10.1007/s10661-0133072-z (2013).

32 Sa CSA and Boaventura RAR, Biodegradation of phenol by Pseudomonas putida DSM 548 in a trickling bed reactor. Biochem Eng J 9: 211-219 (2001).

33 Murat Hocaoglu S, Insel G, Ubay Cokgor E, Baban A and Orhon D, COD fractionation and biodegradation kinetics of segregated domestic wastewater: black and grey water fractions. J Chem Technol Biotechnol 85: 1241-1249 (2010).

34 Mack WN, Mack JP and Ackerson AO, Microbial film development in a Trickling Filter. Institute of water research and department of Microbiology. Microbial Ecol 2: 215-226 (1975).

35 Sedlac R, Phosphorus and Nitrogen Removal from Municipal Waste Water. 2nd edn. Lewis, Florida (1991).

36 Ghanizadeh $\mathrm{G}$ and Sarrafpour R, The effects of temperature and $\mathrm{pH}$ on settlability of activated sludge flocs. Iran J Public Health 30: 139-142 (2001). 
37 Mara D and Horan N, The Handbook of Water and Wastewater Microbiology. Elsevier, London (2003).

38 Bajekal S, and Dharmadhikari N, Use of Polyphosphate accumulating organisms (PAO) for treatment of phosphate sludge. In Proceedings of Taal 2007: The 12th World Lake Conference (918: 922), Jaipur, India (2007).

39 Henze M, Biological phosphorus removal from wastewater: processes and technology. Water Quality International, July/August, 32-36 (1996).

40 Wenzel MC and Ekama GA, Principles in the design of single sludge activated sludge systems for biological removal of carbon, nitrogen and phosphorus, ed by La dephosphatation des eaux uses, CEBEDOC, Belgium, pp 13-26 (1997).

41 Peng YZ, Wu CY, Wang RD and Li XL, Denitrifying phosphorus removal with nitrite by a real-time step feed sequencing batch reactor. J Chem Technol Biotechnol 86: 541-546 (2011).

42 Lens P, Massone A, Rozzi A and Verstraete W,Effect of sulfate concentration and scraping on aerobic fixed biofilm reactors. Water Res 29: 857-870 (1995).

43 Joannis C, Delia ML and Riba JP,Comparison of four methods for quantification of biofilms in biphasic cultures. Biotechnol tech 12: 777-782 (1998).

44 Koch A L, Turbidity measurements in microbiology. ASM News 50: 473-477 (1984).

45 Bragadeeswaran S, Balasubramanian ST, Raffi SM and Rani SS, Scanning electron microscopy elemental studies of primary film. WASJ 10: 169-172 (2010).

46 Eighmy TT, Maratea D and Bishop PL, Electron microscopy examination of wastewater biofilm formation and structural components. Appl Environ Microbiol 45: 1921-1931 (1983).

47 Wojnowska-Baryła I, Cydzik-Kwiatkowska A and Zielińska M, The Application of Molecular Techniques to the Study of Wastewater Treatment Systems, in Bioremediation: Methods and Protocols, ed by Cummings SP. Springer Protocols, USA. pp. 157-183(2010).

48 Uhlich GA, Cooke PH and Solomon EB, Analyses of the red-dry-rough phenotype of an Escherichia coli O157:H7 strain and its role in biofilm formation and resistance to antibacterial agents. Appl Environ Microbiol 72: 2564-2572 (2006).

49 Wood TK, González Barrios AF, Herzberg M and Lee J, Motility influences biofilm architecture in Escherichia coli. Appl Microbiol Biot 72: 361-367 (2006). 
50 O'Toole GA and Kolter R, Flagellar and twitching motility are necessary for Pseudomonas aerouginosa biofilm development. Mol Microbiol 30: 295-304 (1998).

51 Yabannavar A and Bartha R, Biodegradability of some food packaging materials in soil. Soil Biol Biochem 25: 1469-1475 (1993).

52 Nicolai RE and Lefers RM, Workshop on Agricultural Air Quality Biofilters Used to Reduce Emissions from Livestock Housing: A review. South Dakota State University, Brookings, South Dakota, pp 952-1014 (2006).

53 Hirai M, Kamamoto M, Yani, M and Shoda M, Comparison of the biological H2S removal characteristics among four inorganic packing materials. J Biosci Bioeng 91: 396-402 (2001).

54 Kiatkamjornwong S, Sonsuk M, Wittayapichet S, Prasassarakich P and Vejjanukroh PC, Degradation of styrene-g-cassava starchfilled polystyrene plastics. Polym Degrad Stab 66: 323335 (1999).

55 Klrbas Z, Keskin N and Güner A (1999). Biodegradation of Polyvinylchloride (PVC) by White Rot Fungi. Bull Environ Cont Toxicol 63: 335-342 (1999).

56 Arboleda CE, Mejía AIG and López BLO, Poly (Vinylalcohol-Co-Ethylene) Biodegradation on Semi Solid Fermentation by Phanerochaete chrysosporium. Acta Farm Bon 23: 123-128 (2004).

57 Drímal P, Hoffmann J and Družbík M, Evaluating the aerobicbiodegradability of plastics in soil environments through GC and IR analysis of gaseous phase. Polym Test 26: 729-741 (2007).

58 Seal, K. J., and L. H. G. Morton, Chemical materials, In Biotechnology (vol. 8) VCH, Weinheim, Germany, pp 583-606 (1986).

59 Holst O, Stenberg B and Christiansson M, Biotechnological possibilities for waste tyre-rubber treatment. Biodegradation 9(3-4): 301-10 (1998).

60 Linos A and Steinbüchel A, Biodegradation of natural and synthetic rubbers. Biopolymers Online. (2005). DOI: 10.1002/3527600035.bpol2010

61 Rose K and Steinbüchel A, Biodegradation of natural rubber and related compounds: recent insights into a hardly understood catabolic capability of microorganisms. Appl Environ Microbiol 71(6): 2803-12 (2005).

62 Yikmis M and Steinbuchel A, Historical and Recent Achievements in the Field of Microbial Degradation of Natural and Synthetic Rubber. Appl Environ Microbiol 78: 4543-4551 (2012).

This article is protected by copyright. All rights reserved. 
63 Ali Shah A, Hasan F, Shah Z, Kanwal N and Zeb S, Biodegradation of natural and synthetic rubbers: A review. Int Biodeter Biodegr 83: 145-57 (2013).

64 Tsuchii A, Suzuki T and Takeda K, Microbial degradation of natural rubber vulcanizates. Appl Environ Microbiol 50(4): 965-70 (1985).

65 Linos A, Reichelt R, Keller U, Steinbüchel A. A Gram-negative bacterium, identified as Pseudomonas aeruginosa AL98, is a potent degrader of natural rubber and synthetic cis-1, 4-polyisoprene. FEMS Microbiol lett 182(1): 155-61 (2000).

66 Cherian E and Jayachandran K, Microbial degradation of natural rubber latex by a novel species of Bacillus sp. SBS25 isolated from soil. Int J Environ Res 3(4): 599-604 (2009). 


\section{List of Figures and Tables:}

Figure. 1 X-ray Photoelectron Spectroscopic (XPS) analysis of TDR media.
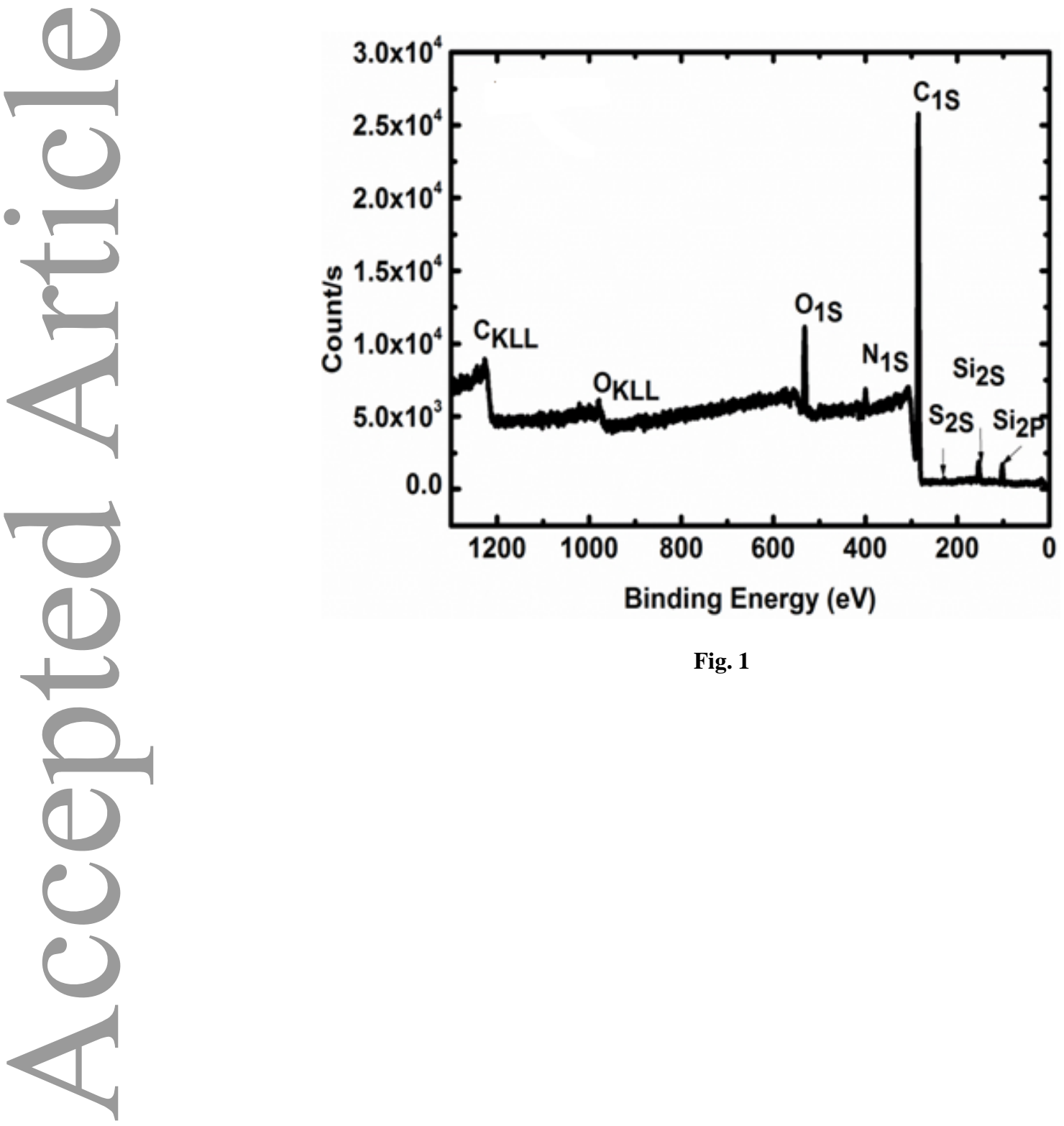

Fig. 1 
Figure. 2 Changes in the levels of COD (A), BOD (B) DO (C) and pH (D) in the activated sludge during development of biofilm on TDR media under aerobic and anaerobic conditions.
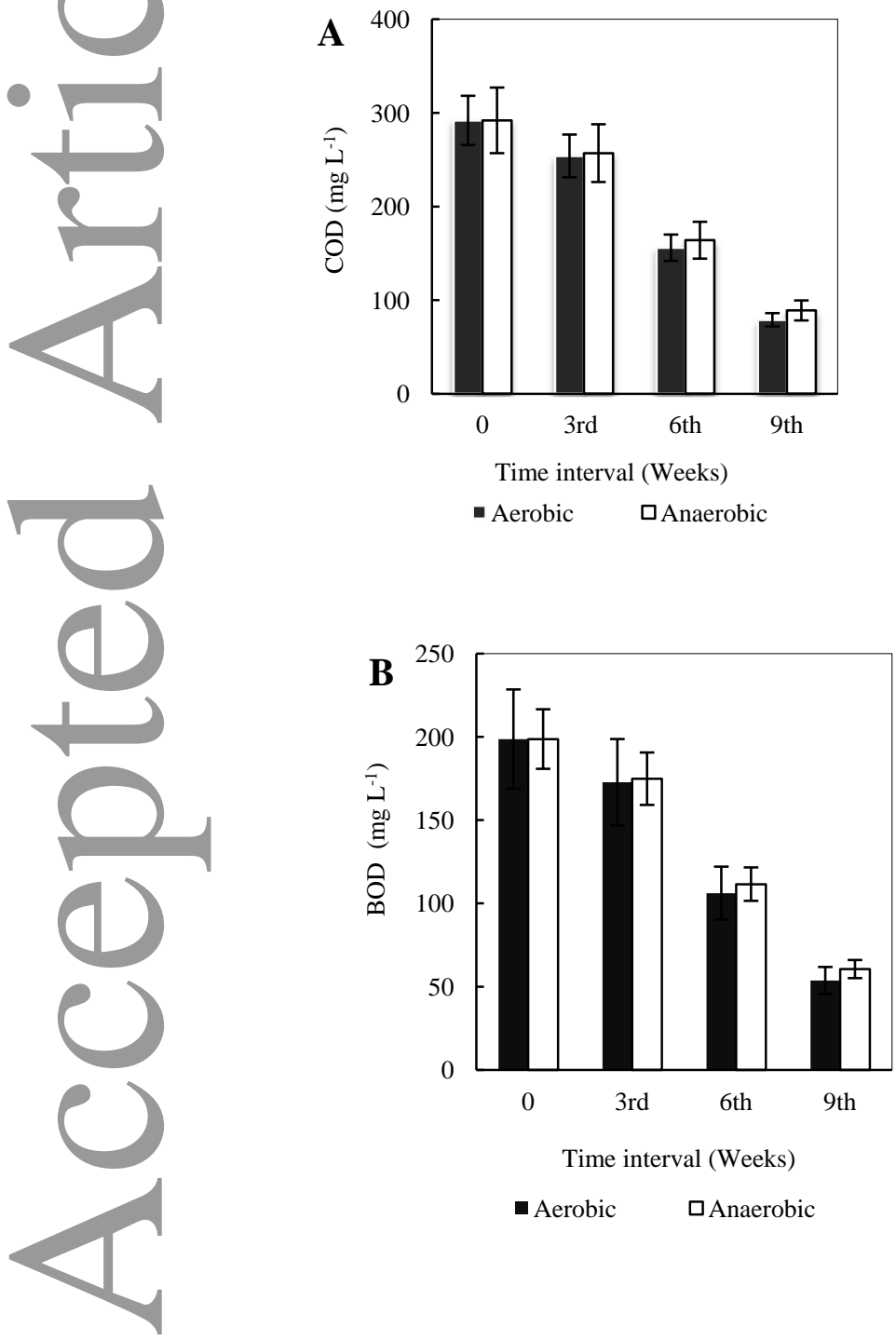

This article is protected by copyright. All rights reserved. 


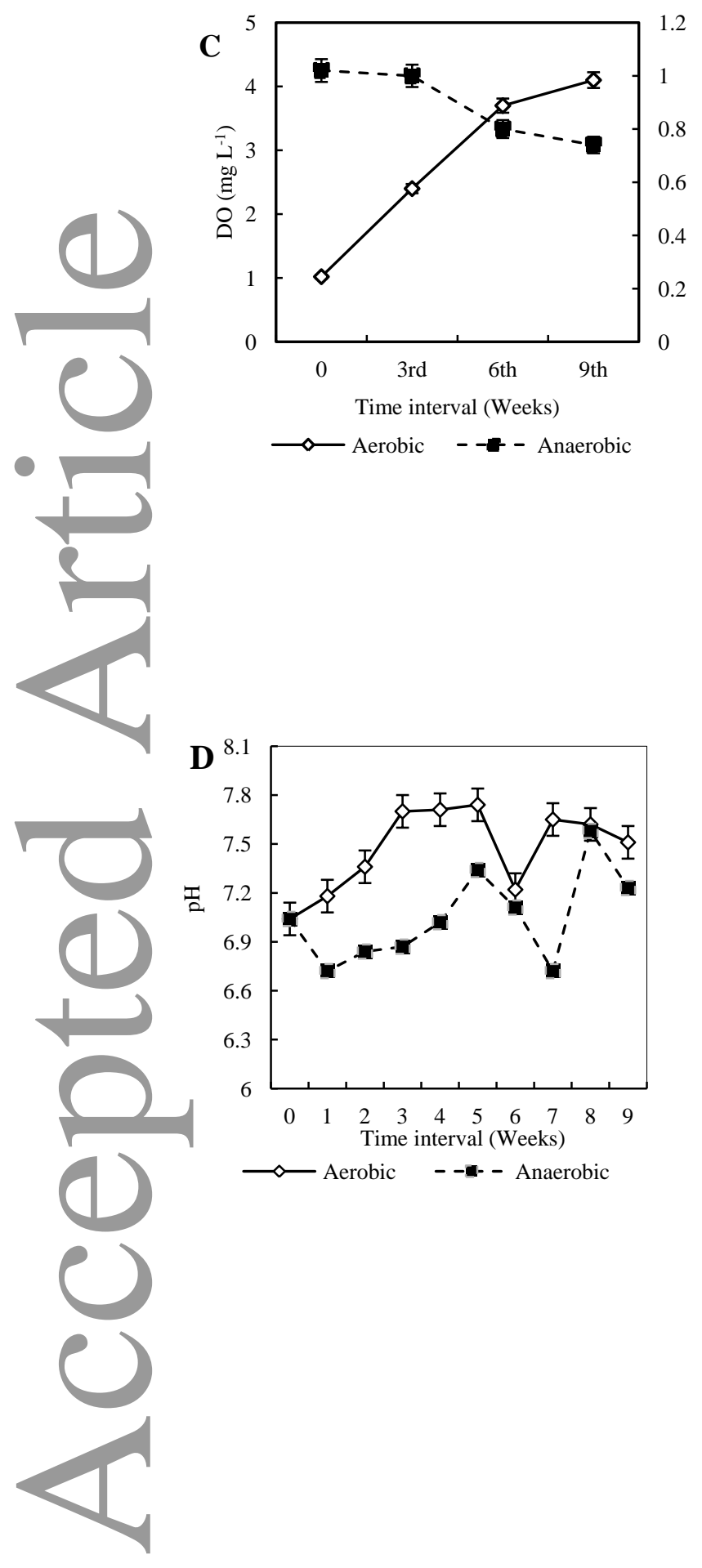

Figure 2

This article is protected by copyright. All rights reserved. 
Figure. 3 Changes in the concentrations of Nitrites (A), Nitrates (B), Phosphates(C) and Sulphates (D) in activated sludge during development of biofilm on TDR media under aerobic and anaerobic conditions.
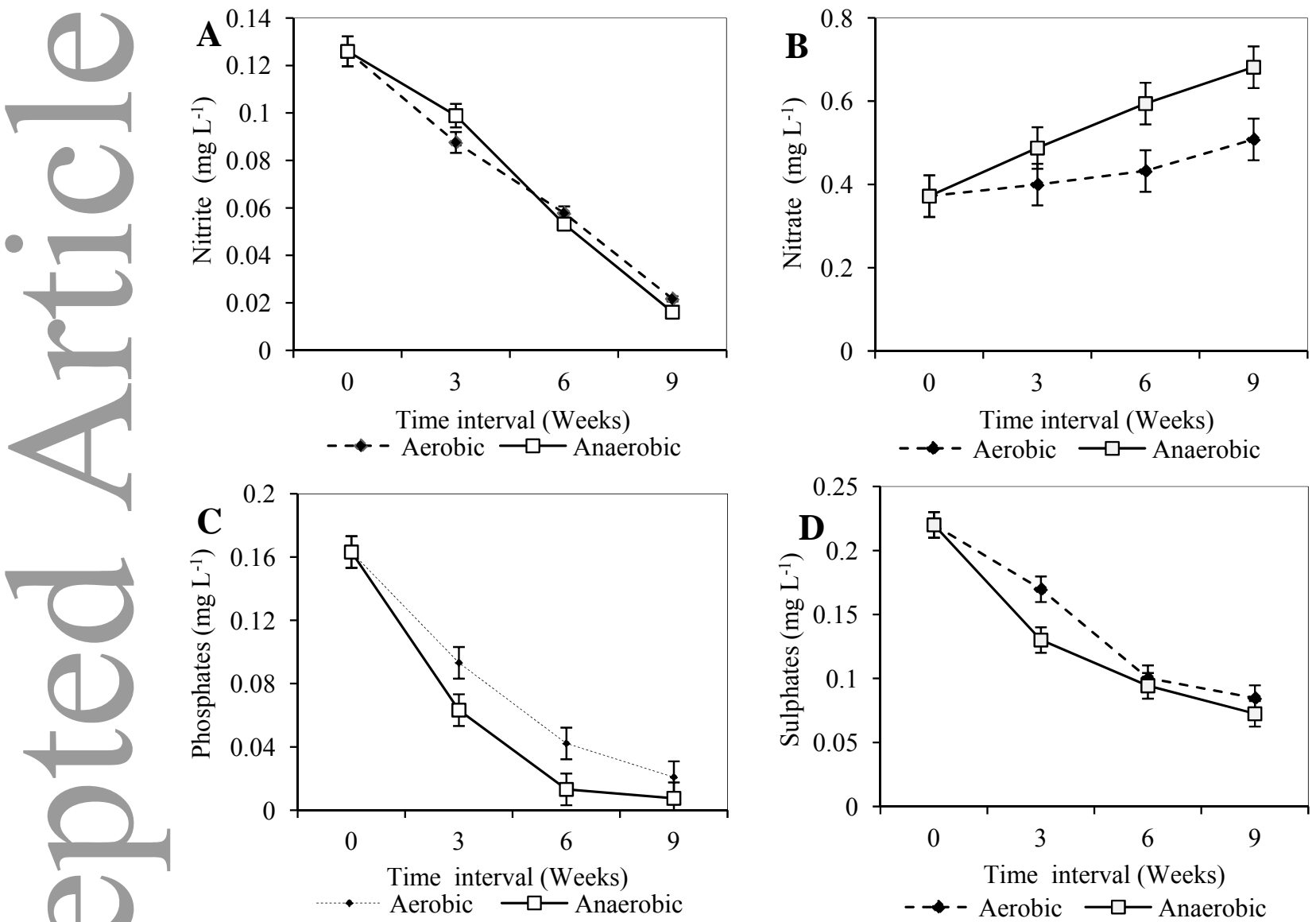

Figure 3 
Figure. 4 Changes in the biofilm OD (A), aerobic weight (B) and anaerobic weight (B) during development on TDR media from activated sludge.

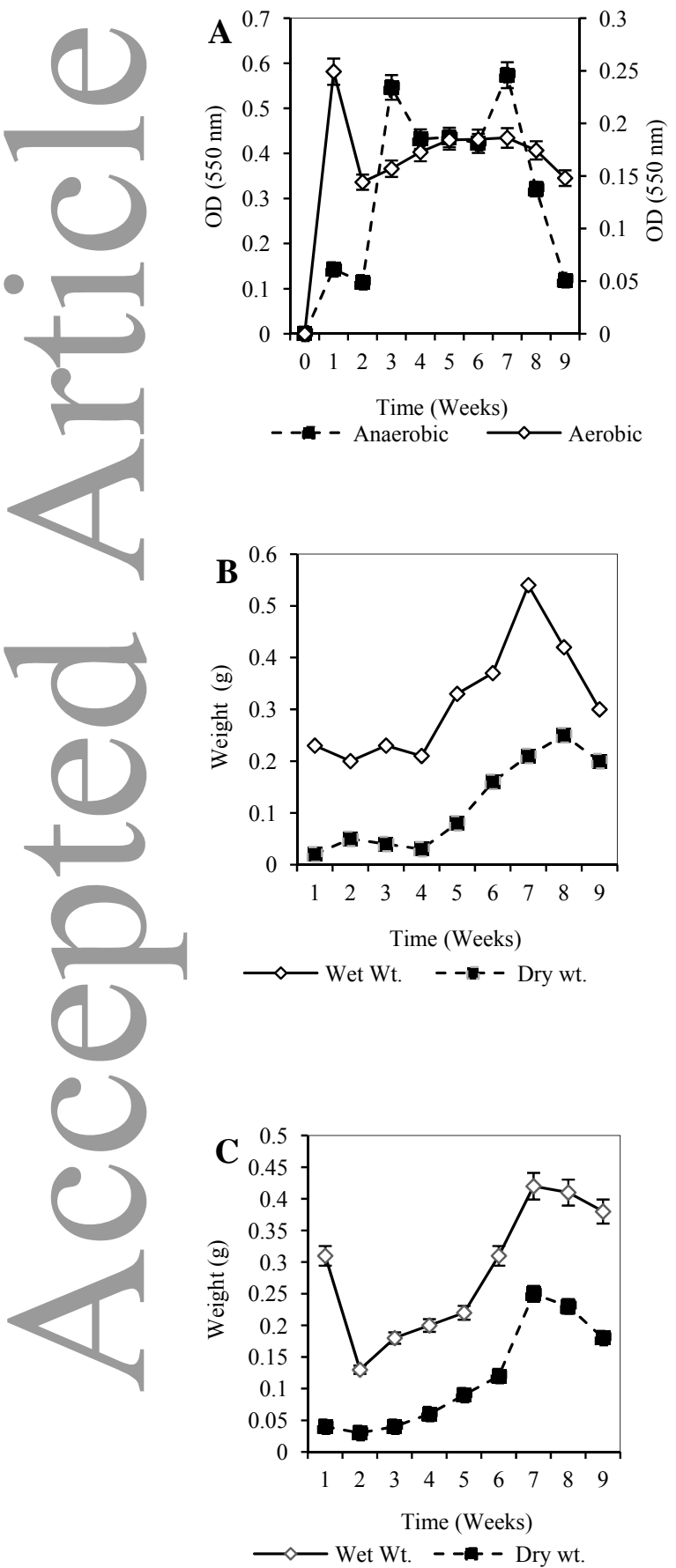

This article is protected by copyright. All rights reserved. 
Figure. 5 SEM micrographs of TDR media and biofilm development. Before colonization of TDR media (A), $3^{\text {rd }}(\mathrm{B}), 6^{\text {th }}(\mathrm{C})$ and $9^{\text {th }}(\mathrm{D})$ weeks biofilms formed under aerobic conditions. While $3^{\text {rd }}(\mathrm{E}), 6^{\text {th }}(\mathrm{F})$ and $9^{\text {th }}(\mathrm{G})$ week (with an abundant exopolymeric matrix) biofilms originated under anaerobic conditions.

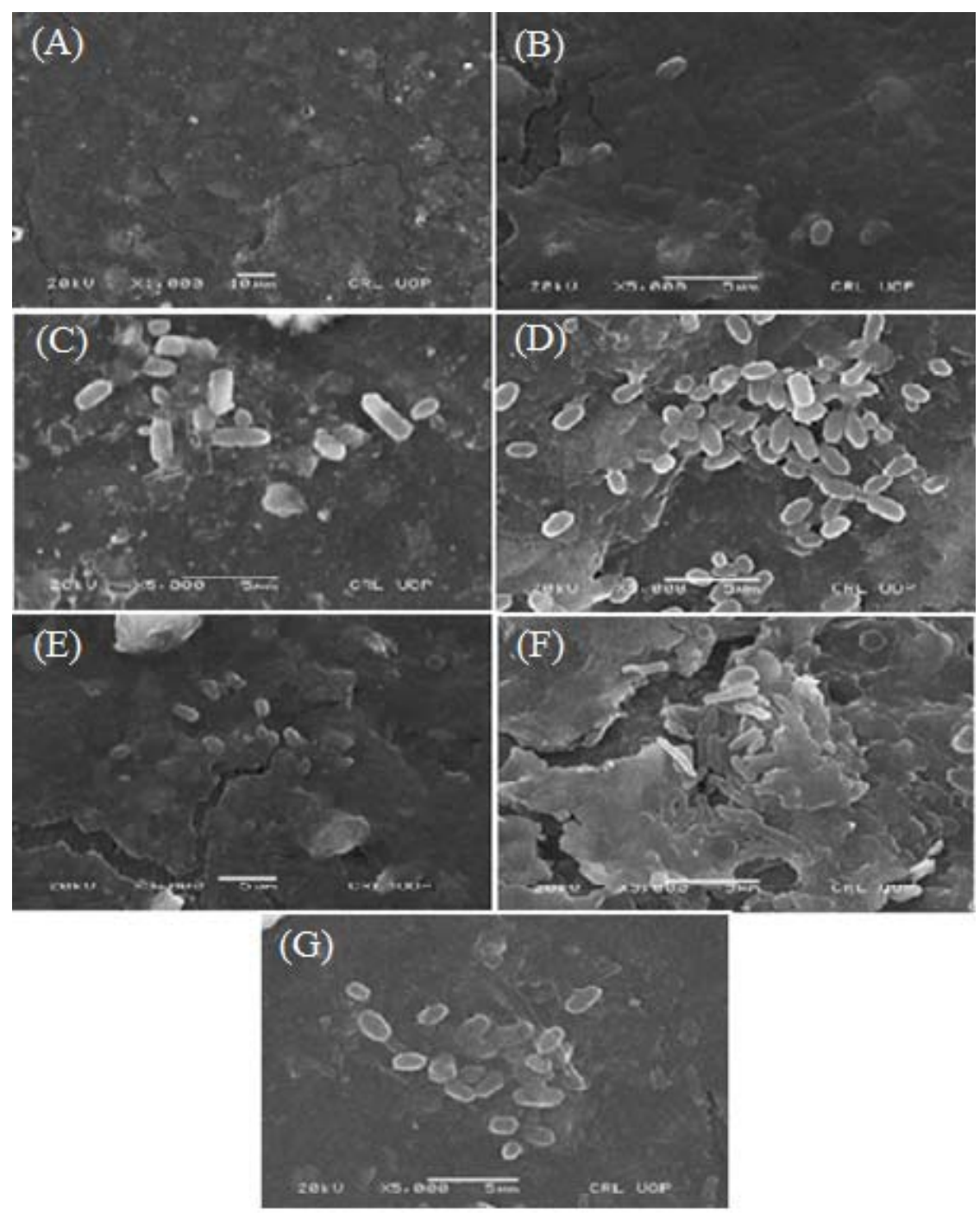

Figure 5 
Figure. 6 Heterotrophic plate count per $\mathrm{mL}$ during development of biofilm on TDR media under aerobic (A) and anaerobic conditions (B) from activated sludge.
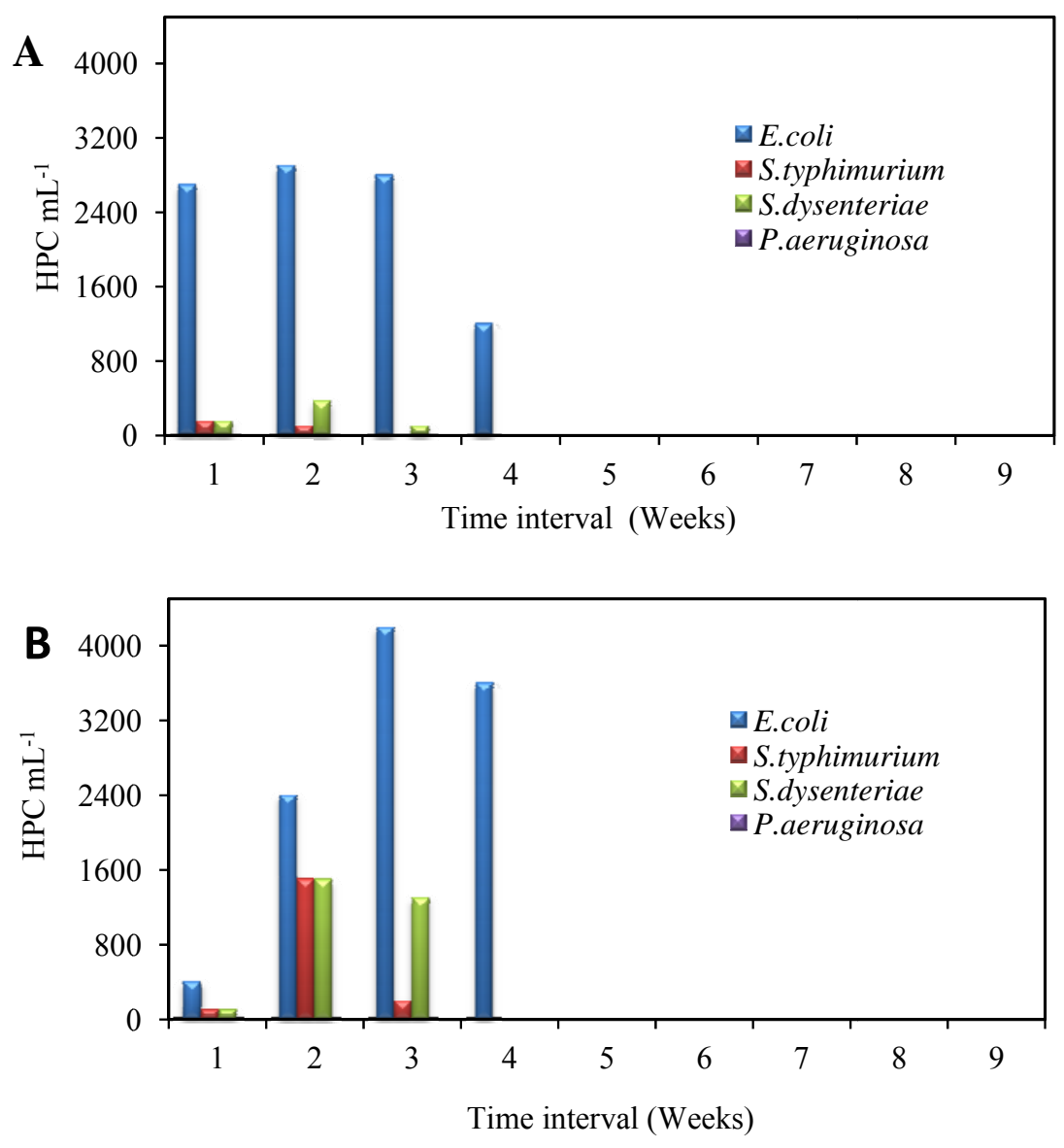

Figure 6 
Figure. 7 FTIR spectra of considerable changes in the TDR media under aerobic (A) and anaerobic conditions (B) till first six weeks of incubation with activated sludge.
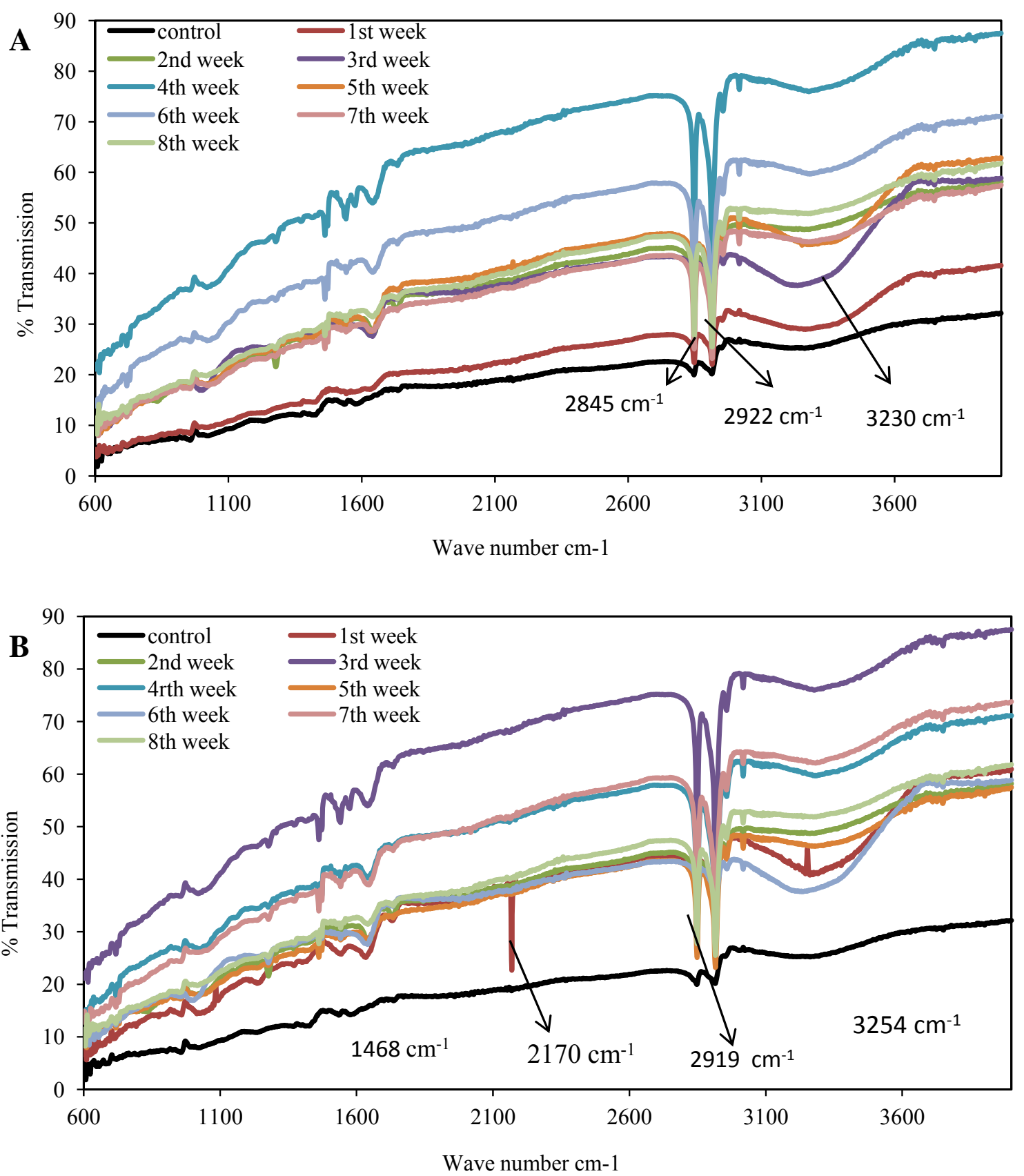

This article is protected by copyright. All rights reserved. 
Table 1.Composition of the activated sludge used for the development of biofilm on TDR media under aerobic and anaerobic conditions

Table 1

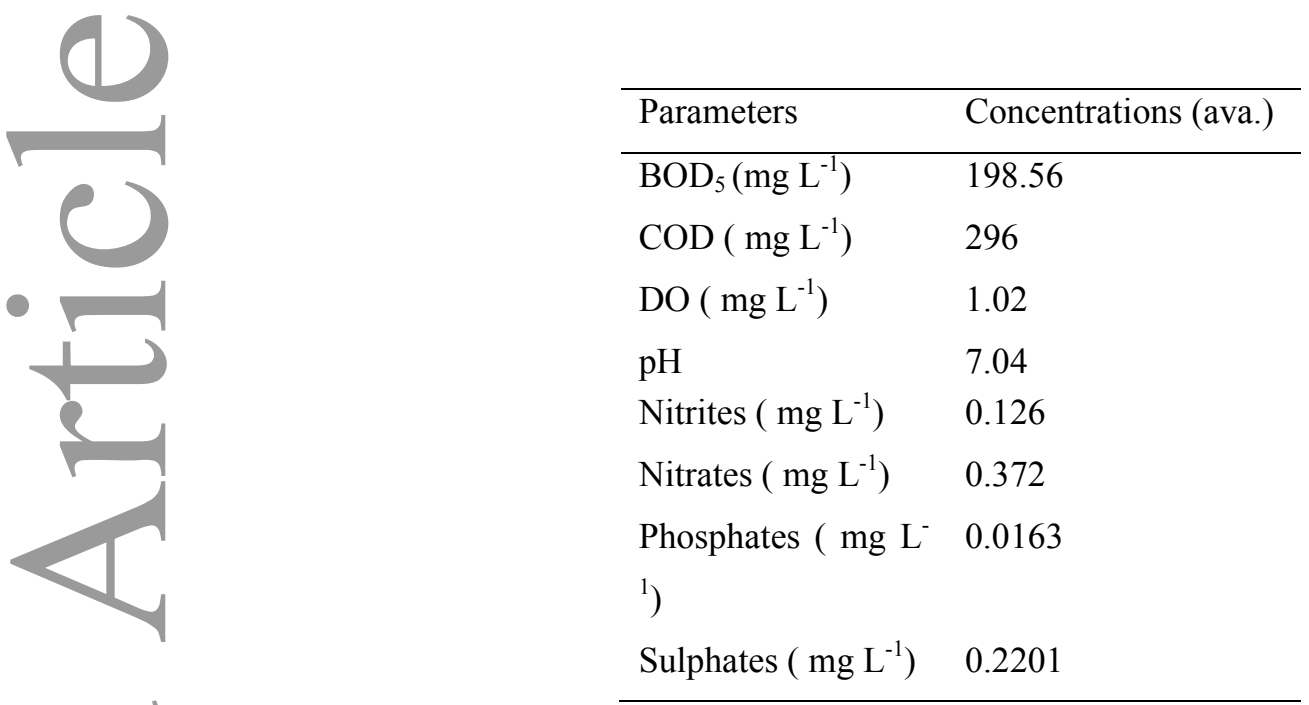


Table 2. MPN Index of E. coli and Fecal coliforms in the sludge before and after the development of biofilm on TDR media under aerobic and anaerobic conditions

Table 2.

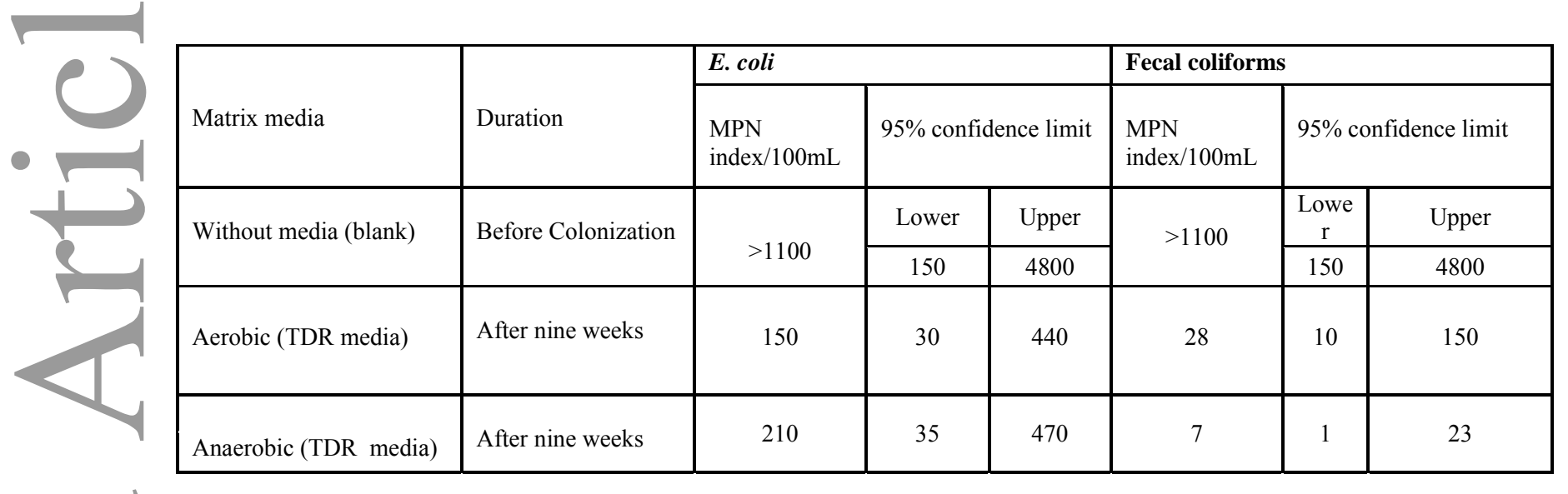

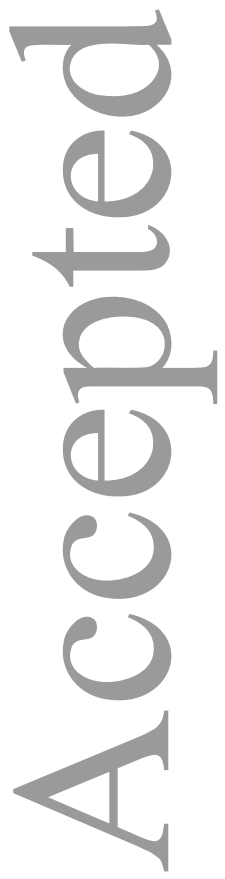

